\title{
Mutations in the Hormone Regulatory Element of Mouse Mammary Tumor Virus Differentially Affect the Response to Progestins, Androgens, and Glucocorticoids
}

\author{
PETER L. GOWLAND AND ELENA BUETTI* \\ Swiss Institute for Experimental Cancer Research, CH-1066 Epalinges, Switzerland
}

Received 14 March 1989/Accepted 8 June 1989

\begin{abstract}
Transcription of the mouse mammary tumor virus DNA is known to be induced by several steroid hormones. Using chimeric MMTV plasmids containing mutations within the hormone regulatory element, we have previously studied the regions required for the glucocorticoid response in mouse fibroblasts. Here we report the characterization of elements essential for the stimulation by progestins and androgens as compared with glucocorticoids. The same set of mutant plasmids was transfected into the human mammary tumor cell line T47D, and the specific transcripts were analyzed by an S1 nuclease protection assay. Androgen-mediated stimulation, although weak, showed an extended sensitivity to mutations, with a slight preference for the proximal region. The results with progestin suggest that sequences within all the described sites protected by the receptor in vitro are required and that the promoter-proximal region ( -128 to -78 from the RNA start site) is more important than the distal one $(-190$ to -160$)$. Moreover, a binding site for nuclear factor I was not required for the progestin response, whereas it was required for glucocorticoids. Thus, the various steroid receptors play a role in the differential regulation of mouse mammary tumor virus transcription by recognizing distinct sequence differences in the hormone regulatory element and interacting with different factors bound to the promoter.
\end{abstract}

The mouse mammary tumor virus (MMTV) has been successfully used as a model for studying the control of gene expression by steroid hormones (reviewed in references 41 and 54). In particular, glucocorticoids have been shown to stimulate MMTV transcription in infected cells $(42,55)$ through the action of the glucocorticoid receptor. Mainly because of the widespread occurrence of this receptor in cultured cell lines, the DNA sequences required for glucocorticoid regulation have been investigated in more detail by using cells transfected with chimeric DNA molecules $(25,28)$ and have subsequently been mapped to the 200 base pairs (bp) upstream of the MMTV RNA start site in the viral long terminal repeat (LTR) $(4,26,31)$. Using a series of mutant plasmids containing clustered point mutations, small deletions, or additions, we demonstrated that maximal stimulation by glucocorticoids requires the cooperative action of multiple, distinct sequence elements $(5,27)$. The strongest, distal element maps at -181 to -172 , inside an area that binds the purified glucocorticoid receptor $(39,44)$. Further elements map around -120 , in one of the three proximal receptor-binding sites (43), and in the symmetric sequence around -70 recognized by nuclear factor I (NF-I $[35,38])$.

MMTV primarily causes carcinomas of the mammary gland, where proviral transcription mainly takes place (52). The physiological effects of other hormones in this tissue suggest that steroid hormones other than glucocorticoids have a role in regulating MMTV in vivo (51). Progestins and androgens, but not estrogens, have recently been reported to stimulate transcription from MMTV LTR constructs introduced into cell lines that express the respective receptors $(8$, 12). By using heterologous constructs, it has been shown (7) that a DNA fragment from -236 to -52 conferred responsiveness to progestins and androgens on the thymidine

\footnotetext{
* Corresponding author
}

kinase $(t k)$ promoter, independently of orientation or distance and in a manner that was dependent on steroidreceptor interactions. This hormone response element (HRE) also provides glucocorticoid stimulation (40), and in fact it contains overlapping in vitro binding sites for both glucocorticoid and progesterone receptors (53). No data regarding androgen receptor binding are as yet available.

In this report we analyze the contribution of specific areas of the HRE to transcriptional regulation by progestins and androgens, as well as glucocorticoids, in responsive mammary cells transfected with a number of the mutants described previously $(5,27)$. The results provide evidence that in the natural context of the MMTV promoter, the proximal upstream region is more important than the distal one for the progestin and possibly the androgen responses and that the NF-I binding site is not required for the progestin response, in contrast to the situation observed with glucocorticoids. It is suggested that subtle sequence and/or spacing variations can be recognized by individual steroid receptors (possibly in conjunction with other factors) to achieve differential regulation of transcription.

\section{MATERIALS AND METHODS}

Plasmid constructions. The chimeric MMTV LTR- $t k$ plasmids in which the HindIII linker 5'-CAAGCTTG-3' was inserted at various positions in the HRE have been described previously (27). Such mutants were named according to the position of the LTR nucleotides immediately flanking the linker. The mutants $151 / 145$ ins and $201 / 192$ ins were constructed by inserting a 123-bp HindIII fragment of mouse DNA (27) into the respective linker mutants.

Cell culture and transfection. T47D cells were grown in Dulbecco modified Eagle medium supplemented with $10 \%$ fetal calf serum, bovine insulin $(0.6 \mu \mathrm{g} / \mathrm{ml})$, and antibiotics. Subconfluent cells were transfected transiently by the 
DEAE-dextran method essentially as described previously (8), except that the treatment with chloroquine diphosphate was reduced to $1 \mathrm{~h}$, the dimethyl sulfoxide shock was omitted, and $1 \mu \mathrm{g}$ of plasmid pH514 was cotransfected with $10 \mu \mathrm{g}$ of the MMTV plasmid per $10-\mathrm{cm}$ petri dish. pH514 contains the rabbit $\beta$-globin gene (33) and the simian virus 40 enhancer sequences (1) in a pAT153 vector. After $16 \mathrm{~h}$, hormones were added in fresh medium, and the cells were incubated for a further $40 \mathrm{~h}$ before being harvested. Stable transfections were performed by two different methods: calcium phosphate precipitation (18) and electroporation (37). For the calcium procedure, either supercoiled or EcoRI-linearized MMTV test plasmids (6 to $8 \mu \mathrm{g}$ ) were coprecipitated with $1.2 \mu \mathrm{g}$ of the plasmid pSV2neo (47) and $8 \mu \mathrm{g}$ of carrier herring sperm DNA onto a $6-\mathrm{cm}$ petri dish of subconfluent T47D cells. In one series of transfections, 2.5 or $5 \mu \mathrm{g}$ of an expression plasmid for the human glucocorticoid receptor gene (pRSV-hGR $\alpha$ [16]) was included in the mixture of precipitated DNA. After $15 \mathrm{~h}, 0.1 \mathrm{mM}$ chloroquine diphosphate (30) was added to the medium for $2 \mathrm{~h}$, and a glycerol shock ( $20 \%$ glycerol in medium, 2 min at room temperature) was applied. After several washes, normal medium was added for 2.5 days, and then the selection was started, with $300 \mu \mathrm{g}$ of G418 sulfate (GIBCO Laboratories, Grand Island, N.Y.) per ml. Most cells had detached after 10 days, and resistant clones were visible after another 1 to 2 weeks. Individual clones or pools of clones were expanded for RNA and DNA analysis. Electroporation was performed with an electronic cell-processing centrifuge coupled to a high-voltage processor (D. E. P. Systems, Inc., Troy, Mich.). Cells in suspension $\left(10^{5}\right)$ were spun through $0.35 \mathrm{M}$ sucrose onto the electrode plate overlaid with $10 \mu \mathrm{g}$ of DNA solution in $0.4 \mathrm{M}$ sucrose. Two pulses of 800 to $1,000 \mathrm{~V}$, lasting $30 \mu \mathrm{s}$ each, were applied: the first after $1 \mathrm{~min}$ at 300 $\times g$ and the second after $10 \mathrm{~s}$ during which the speed was increased to approximately $1,200 \times g$. The DNA solution contained $5 \mu \mathrm{g}$ of linearized MMTV plasmid and $1.5 \mu \mathrm{g}$ of a linearized plasmid containing the hygromycin B resistance gene (2) under the control of the simian virus 40 promoter. After the treatment, the cells were seeded in $6-\mathrm{cm}$ petri dishes. The medium was changed the next day, and selection was started 2 days later with $25 \mu \mathrm{g}$ of hygromycin B (Boehringer GmbH, Mannheim, Federal Republic of Germany) per $\mathrm{ml}$. Up to 10 clones per plate were visible under the phase-contrast microscope after about 2 weeks. They were later pooled and expanded for nucleic acid extraction. At 20 to $40 \mathrm{~h}$ prior to RNA isolation, the cultures received fresh medium plus $10^{-3}$ volume of ethanol with or without hormones. The concentrations used were $10^{-8}$ M R5020 (17, 21-dimethyl-19-nor-4,9-pregnadiene-3,20-dione, a synthetic progestin [Du Pont, NEN Research Products, Boston, Mass.]), $10^{-7} \mathrm{M}$ dihydrotestosterone, and $10^{-6} \mathrm{M}$ dexamethasone (a synthetic glucocorticoid) (both from Sigma Chemical Co., St. Louis, Mo.). In stable transfectants, the presence of integrated plasmid DNA was assayed by Southern blotting (46) with an LTR-specific probe. Digestion with the enzyme BamHI revealed the intactness of the LTR, and digestion with EcoRI (which cuts once in the plasmid) gave an estimate of the arrangement and number of integrated plasmids. Electroporation led mainly to the integration of single DNA molecules, with one exception (the pool 189/180 [see Fig. 3]). The calcium precipitation method gave rise to both single- and multiple-copy transfectants (data not shown).

Nucleic acid analysis. DNA and total cytoplasmic RNA were isolated from stably transfected cells by Nonidet P-40 lysis as described previously (4). RNA from transiently transfected cells was prepared as described previously (32). DNA (46) and RNA blot analyses were performed as described previously (3). For determinations of actin mRNA content, slot blots with 2 or $5 \mu \mathrm{g}$ of total transfected-cell RNA were hybridized for $20 \mathrm{~h}$ at $60^{\circ} \mathrm{C}$ with a random primer radioactively labeled (14) PstI fragment of mouse $\beta$-actin cDNA (36) in $4 \times \mathrm{SSC}(1 \times \mathrm{SSC}$ is $0.15 \mathrm{M} \mathrm{NaCl}$ plus $0.015 \mathrm{M}$ sodium citrate) and washed in $0.1 \times \mathrm{SSC}$ at $50^{\circ} \mathrm{C}$. Similar RNA dot blots were hybridized to a DNA probe representing the $0.45-\mathrm{kbp} B g$ lII fragment in the N-terminal half of the human glucocorticoid receptor (23) and gave a positive signal in untransfected T47D cells (data not shown). S1 nuclease protection assays were carried out with $50 \mu \mathrm{g}$ of RNA and 5'-32 P-labeled DNA probes: for MMTV, an LTR fragment spanning the nucleotides from -204 to +134 ; for $\beta$-globin, BamHI-digested plasmid H514 (27); and for the glucocorticoid receptor, a 6-kbp $B$ glII fragment of the plasmid pRSV-hGR $\alpha$ (16). Protected fragments were separated on denaturing $6 \%$ polyacrylamide gels (34). Bands were visualized by autoradiography at $-70^{\circ} \mathrm{C}$ with X-Omat AR films (Eastman Kodak Co., Rochester, N.Y.) and intensifying screens, and their intensities were quantified by densitometry after various exposure times.

DNase I footprinting. Cells were lysed by nonionic detergents, and nuclear extracts were prepared by extraction with $100 \mathrm{mM}$ salt and ammonium sulfate precipitation by the method of Siebenlist et al. (45) for $\mathrm{Ltk}^{-}$cells and by the method of Gorski et al. (17) for T47D cells. DNase I protection experiments (15) were performed by the method of Lichtsteiner et al. (29), using as a probe the 445-bp StyI-BamHI fragment of the MMTV LTR from -306 to the $3^{\prime}$ end of the LTR $\left(3^{\prime}-{ }^{32} \mathrm{P}\right.$ end labeled in the coding strand at the BamHI site of the linker at +139 with $\left[\alpha-{ }^{32} \mathrm{P}\right] \mathrm{dGTP}$ and Klenow DNA polymerase). The probe was incubated at $0^{\circ} \mathrm{C}$ for $15 \mathrm{~min}$ with or without nuclear extracts, in the presence of $50 \mu \mathrm{g}$ of poly $(\mathrm{dI}: \mathrm{dC})$ per ml. After limited DNase digestion, the deproteinized DNA was analyzed on a denaturing $5 \%$ polyacrylamide gel, along with the product of a sequencing reaction of the probe (34).

\section{RESULTS}

The plasmids used in this study consist of an MMTV LTR linked to the coding sequence of the $t k$ gene of herpes

FIG. 1. (A) Diagram of the HRE of the MMTV LTR- $t k$ plasmid upstream of the RNA start site $(+1)$ and sequences of relevant areas (13). Symbols: IIIIII , DNA segments protected in vitro against DNase I by the glucocorticoid receptor (44); $\downarrow$, limits of exonuclease III footprints of the glucocorticoid $(\mathrm{G})$ or progesterone $(\mathrm{P})$ receptors $(53): \longleftrightarrow$ (centered at position -70 ), dyad-symmetrical sequence that binds NF-I in vitro (38). Symbols for previously defined transcriptional control elements for glucocorticoid hormones: ${ }^{2}$, distal and proximal elements , NF-I element; $\square$, TATA homology (5). (B) Structure of the mutant 129/88 DBS + (27). HindIII linkers are present at both sides of the insert, which has the sequence of the distal receptor-binding site (DBS). (C) Structure of the mutant 151/145 ins spacer. A 123-bp HindIII fragment of mouse DNA (27) was inserted in the mutant 151/145. The mutant 201/192 ins spacer contains the same spacer in the same orientation inserted into the HindIII site between -201 and -192. (D) Sequence of the LTR segments containing the mutations (sense strand). The HindIII linker in the mutants is underlined. (In the mutant 140/132, the last $G$ of the linker was deleted in the cloning.) In the reference wild-type sequence, a double line denotes the DNase I footprints of progesterone receptor on the sense strand (11). 
A)

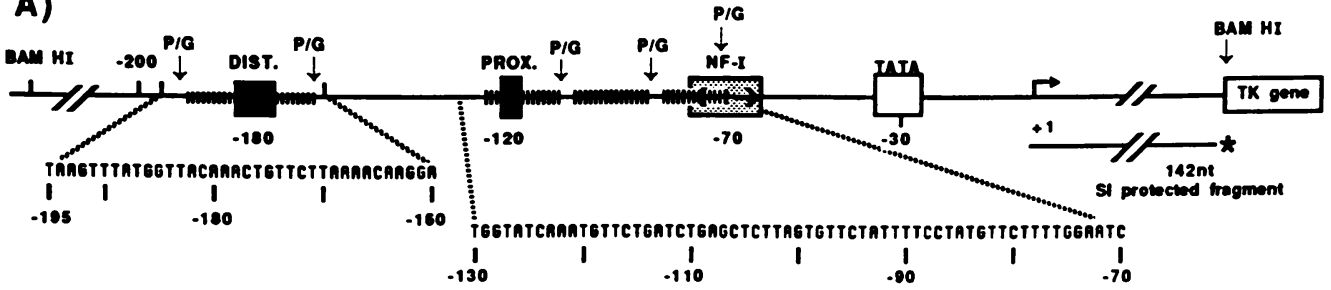

B)

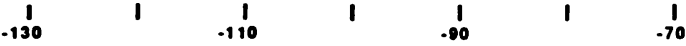

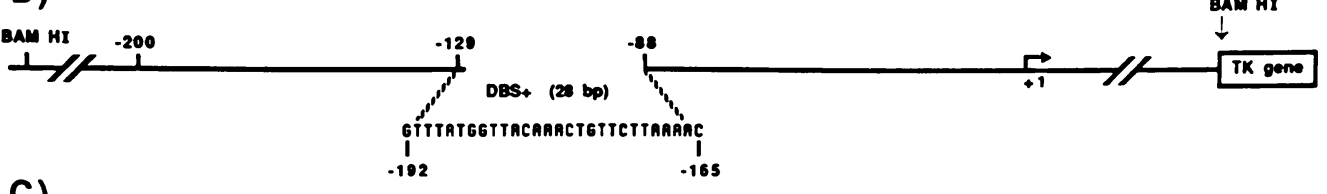

C)

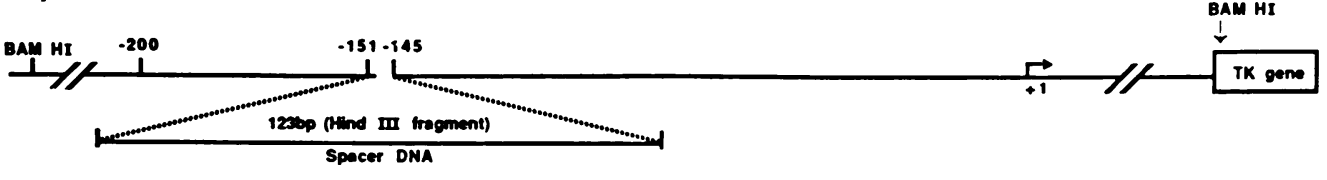

D)

wt 'TtAAATAAGTITATGGTTACÁAACTGTTCTIAAAACAAGGÁGGTGAGACAÁgTGGTTTCCTGAGTTGGTT'

196/186 TTAAACAAGCTTGGGTTACAAACTGTTCTTAAAACAAGGATGTGAGACAAGTGGTTTCCTGAGTTGGTTT

190/181 TTAAATAAGTTCAAGCTTGCAAACTGTTCTTAAAACAAGGATGTGAGACAAGTGGTTTCCTGAGTTGGTTT

189/180 TTAAATAAGTTTCAAGCTTGAAACTGTTCTTAAAACAAGGATGTGAGACAAGTGGTTTCCTGAGTTGGTTT

186/177 TTAAATAAGTTTATGCAAGCTTGCTGTTCTTAAAACAAGGATGTGAGACAAGTGGTTTCCTGAGTTGGTTT

181/175 TTAAATAAGTTATGGTTACCAAGCTTGGTTCTTAAAACAAGGATGTGAGACAAGTGGTTTCCTGAGTTGGTTT

176/169 TTAAATAGTTTATGGTTACAAACTCAAGCTTGAAAACAAGGATGTGAGACAAGTGGTTTCCTGAGTTGGTTT

176/166 TTAAATAATTTATGGTTACAAACTCAAGCTTGACAAGGATGTGAGACAAGTGGTTTCCTGAGTTGGTTT

193/162 TTAAATAACAAGCTTGGGATGTGAGACAAGTGGTTTCCTGAGTTGGTTT

161/145 TTAAATAAGTTTATGGTTACAAACTGTTCTTAAAACAAGGCAAGCTTGTTTCCTGAGTTGGTTT

151/145 TTAAATAAGTTTATGGTTACAAACTGTTCTTAAACAAGGATGTGAGACACAAGCTTGITTCCTGAGTTGGTTT

140/132 TTAAATAAGTTTATGGTTACAACTGTTCTTAAAACAAGGATGTGAGACAAGTGGTTTCCTCAAGCTITTT

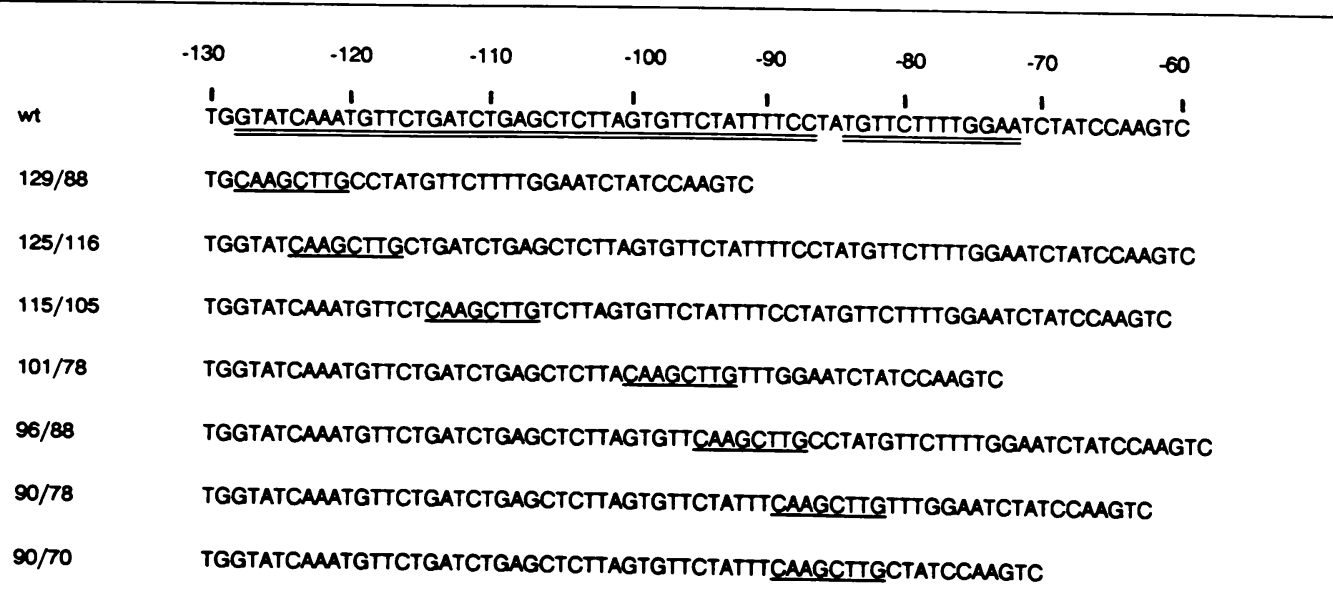




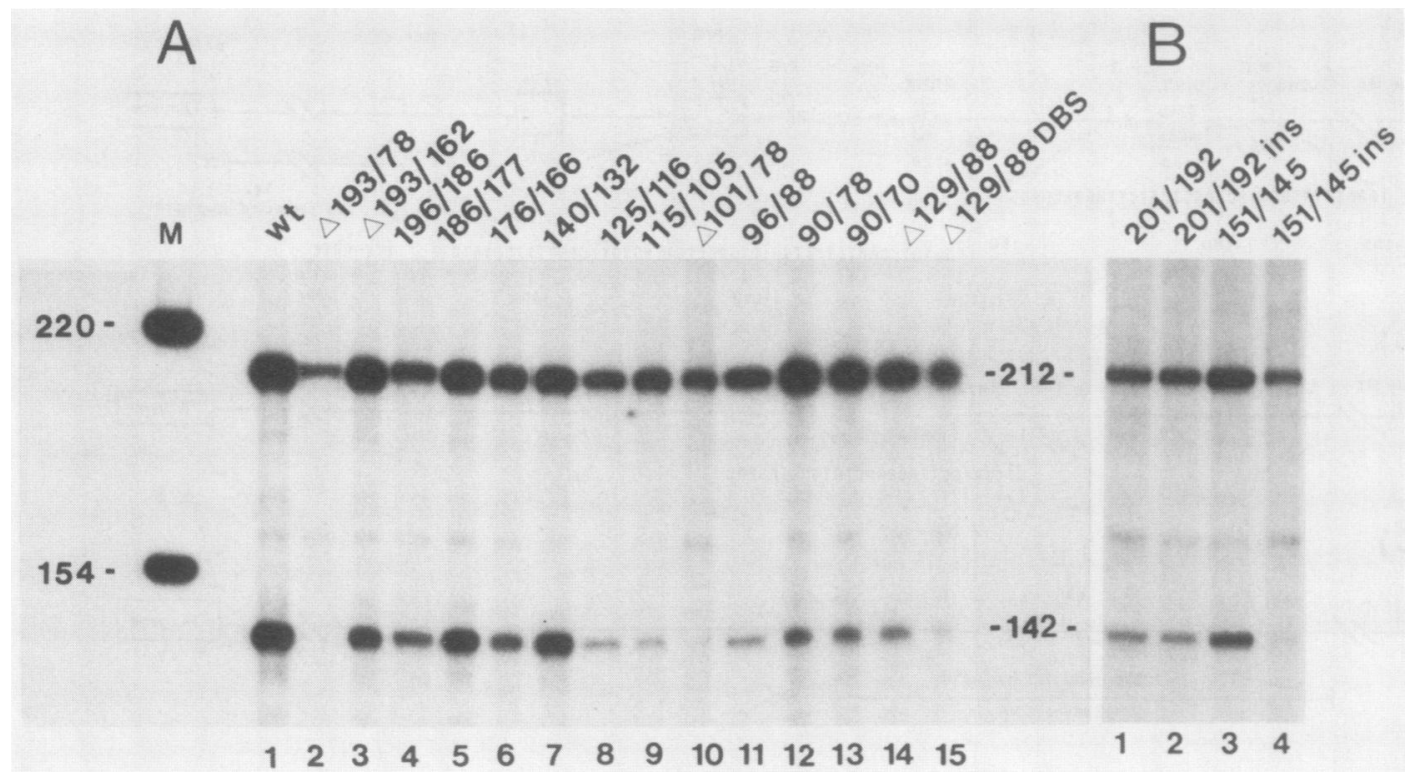

FIG. 2. S1 nuclease protection assay of RNA from T47D cells transiently transfected with MMTV plasmids (as indicated above each lane) plus the control plasmid H514 carrying the rabbit $\beta$-globin gene and treated with R5020. MMTV mRNA protects a fragment of 142 nucleotides, and $\beta$-globin mRNA protects one of 212 nucleotides. (A) Lanes: 1 , wild type; 2 to 15 , mutants; $\mathrm{M}, 3^{\prime}-{ }^{32} \mathrm{P}$-labeled molecular size markers (Hinfl-digested pBR322) (their sizes in nucleotides are given on the left). (B) Comparison of mutants with a 123-bp spacer insertion and the corresponding linker-scanning mutants.

simplex virus and cloned into pBR322 (Fig. 1A). The mutants contain an 8-bp HindIII linker replacing the natural sequence at various locations in the HRE (Fig. 1D). The substitutions leave the neighboring DNA either perfectly aligned or slightly shifted (by 1 to 3 nucleotides), whereas other mutations consist of deletions or insertions of DNA fragments (Fig. 1B and C). Details of the construction of these plasmids, and their functional analysis with respect to the response to glucocorticoid hormones in mouse $\mathrm{Ltk}^{-}$ fibroblasts, have been presented previously $(5,27)$. The constructs were transfected stably or transiently into the human mammary tumor cell line T47D, reported to have retained high levels of the progestin receptor and moderate levels of the androgen receptor but low levels of the glucocorticoid receptor $(10,24)$. The T47D cells used in our experiments did not respond to dexamethasone when transfected with the wild-type MMTV LTR plasmid (data not shown), whereas they did respond when cotransfected with a plasmid expressing the complete cDNA for the human glucocorticoid receptor (see Fig. 3b, lane 4). The ability of the mutants to be transcriptionally stimulated by steroid hormones was analyzed in nuclease $\mathrm{S} 1$ protection experiments with cytoplasmic RNA of transfected cells. In the transient-transfection assays, transcription from a cotransfected plasmid containing the rabbit $\beta$-globin gene with its own promoter and the simian virus 40 enhancer (1) provided an internal standard unaffected by hormones. In stable transfections, the mRNA content of cytoplasmic RNA preparations was standardized by hybridization to a $\beta$-actin probe and did not vary upon hormone treatment. Typical autoradiographs obtained with either transient- or stabletransfection assays are shown in Fig. 2 and 3, respectively. Quantitative data were obtained from densitometry of autoradiographs at different exposure times and are summarized in Table 1.

Induction factors for progestin and androgen were derived from stable transfections with the wild-type plasmid. For the progesterone analog $\mathrm{R} 5020\left(10^{-8} \mathrm{M}\right)$ the induction factor was about 60 -fold, whereas with dihydrotestosterone $\left(10^{-7}\right.$ M) there was a 7-fold stimulation above the basal level (Table 1). In cells cotransfected with the glucocorticoid receptor gene, the induction by dexamethasone was approximately 200 -fold. Transcription without hormone was undetectable in transiently transfected cells, and relative stimulation factors were derived by comparing the levels of RNA transcribed from mutant and wild-type plasmids.

The distal element plays a minor role in progestin stimulation of the promoter. T47D cells transfected with plasmids carrying a deletion between -193 and -78 upstream of the cap site did not show any detectable stimulation of transcription in response to progestin addition (Fig. 2A, lane 2). Hence, the deleted DNA fragment, which contains the four in vitro binding sites for the purified progesterone receptor (53) (Fig. 1A), also contains the functional element(s) required for progestin stimulation of the MMTV promoter. The use of linker-scanning mutants within this region of the LTR allowed us to define in more detail the specific sequences involved. The results of transfection experiments with plasmids mutated in the area between -200 and -160 , which covers the most distal of the in vitro receptor-binding sites, led to the conclusion that this region is less important for the progestin-mediated response than more proximal ones are (Table 1). Deletion of the complete distal receptorbinding site (mutant 193/162) caused a ca. twofold reduction in the progestin response (Fig. 2A, lane 3; Table 1). A comparable reduction was seen, both in stable and in transient transfections, with mutants $176 / 169$ (Fig. 3a, lanes 14 and 15) and 176/166 (Fig. 2A, lane 6), which have lost the consensus hexanucleotide TGTTCT common to all four binding sites for the progesterone receptor (Fig. 1A). In the transient-expression assay, mutations upstream (to -196) or downstream (to -132) gave R5020 stimulation levels comparable to those in the wild type (some values higher than $100 \%$ are not considered different from wild-type values) 


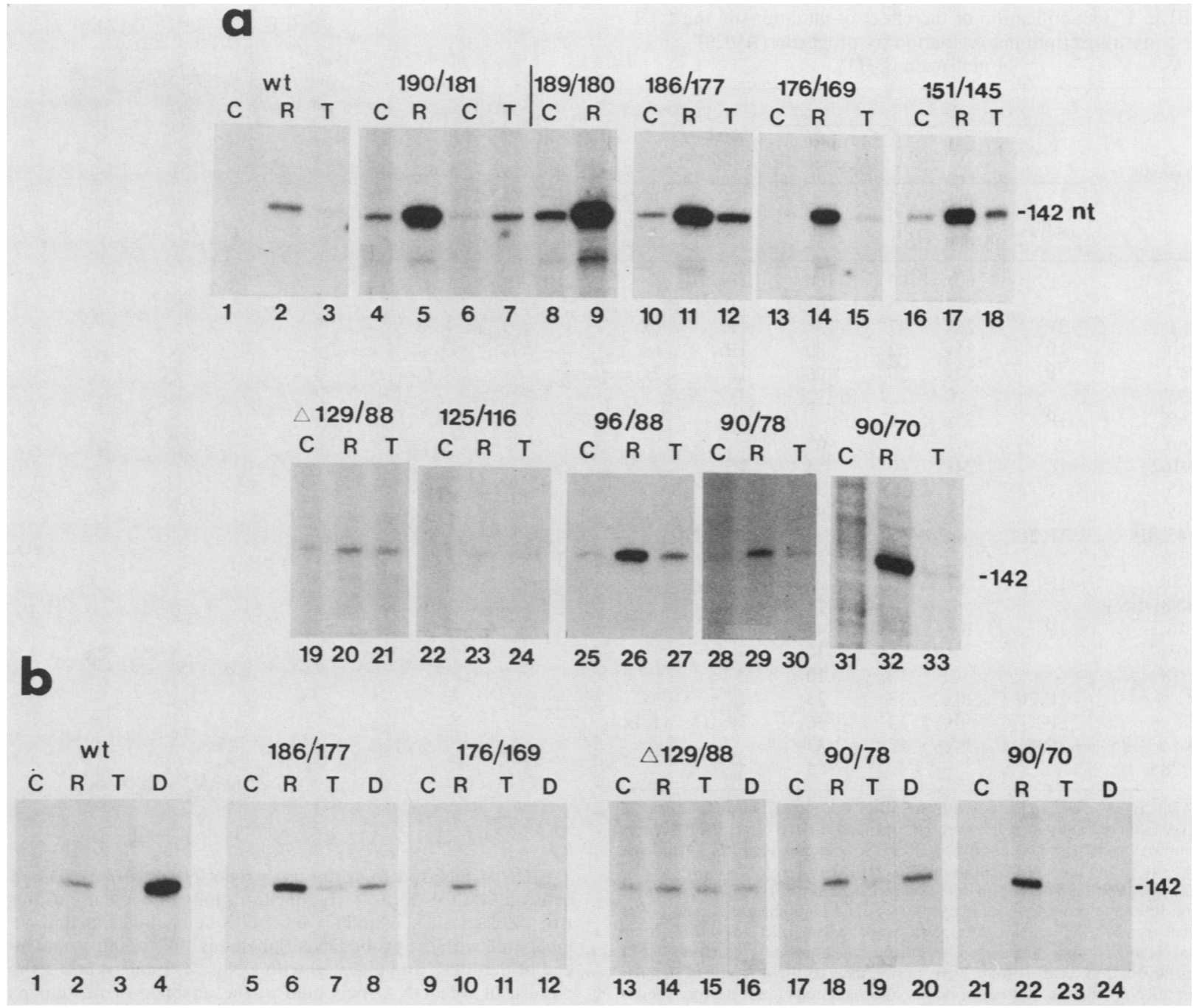

FIG. 3. S1 nuclease protection assays of RNA from T47D cells stably transfected with wild-type (wt) or mutant MMTV plasmids, as indicated above the panels. In panel (b), transfectants also containing the human glucocorticoid receptor gene in an expression vector (pRSV-hGR $\alpha$ [16]) were analyzed for the dexamethasone response. Cultures were treated with ethanol (lanes C), R5020 (lanes R), dihydrotestosterone (lanes T), or dexamethasone (lanes D). Correctly initiated mRNA protects a fragment of 142 nucleotides (nt) from S1 digestion. In lanes 4 to 7 , the hormone treatments were performed in separate experiments, and the relative control lane $(C)$ is shown to the left of each experimental lane. RNA from isolated clones was used in lanes 16 to 18 and 25 to 27 of panel (a) and lanes 21 to 24 of panel (b). The other lanes contain RNA from pools of clones.

(Fig. 2A, lanes 4, 5, and 7; Table 1). With stably transfected cells, for which the ratio between stimulated and basal levels was determined, we observed a two- to threefold reduction with different mutants covering the whole distal region from -190 to -162 (or possibly -145 [Table 1$]$ ). The discrepancy with respect to the data from transient-expression assays, in which absolute stimulated levels are considered, may be explained by differences in the basal levels of transcription (Fig. 3a, lanes 1 to 18 ).

The proximal element is particularly important for the progestin-mediated response. The DNA segment from -125 to -70 contains three promoter-proximal binding sites for the purified progesterone receptor in vitro (53) (Fig. 1A). Mutations of sequences within this area have a more dramatic effect on the progestin-induced transcription level than do mutations in the distal site. Deletion of two of the three proximal binding sites, as in the mutant $129 / 88$, reduced the amount of progestin-stimulated RNA fourfold or more (Fig. 2A, lane 14; Fig. 3a, lanes 19 and 20; Table 1). No increase in the number of transcripts was observed when an oligonucleotide harboring the sequence of the distal receptorbinding site $(-192$ to -165$)$ was inserted into this mutant via the HindIII linker (129/88 DBS+; Fig. 1B). In fact, in transient transfections this construct gave an even lower level of transcription (Fig. 2A, lane 14 versus lane 15; Table 1). The mutants $125 / 116$ and $115 / 105$ directly affect the most upstream of the three proximal binding sites. Both displayed a reduced progestin response (Fig. 2A, lanes 8 and 9; Fig. 3a, lanes 22 and 23; Table 1). The deletion mutant 101/78 lacks the middle binding site and the $5^{\prime}$ boundary of the most proximal one. This mutant showed a stimulation of only $10 \%$ of wild-type levels, the lowest detectable signal in the transient-transfection assays (Fig. 2A, lane 10; Table 1), and the induced levels were extremely low in stable transfectants (data not shown). The plasmid $96 / 88$, in which the mutation affects the middle binding site but leaves all but the last base pair of the consensus hexanucleotide intact, showed a threefold-reduced progestin response (Fig. 2A, lane 11; Fig. 3a, 
TABLE 1. Quantification of the effect of mutations in the LTR on transcriptional regulation by progestin (R5020) or androgen (DHT)

\begin{tabular}{|c|c|c|c|c|c|c|}
\hline \multirow{3}{*}{ Plasmid ${ }^{a}$} & \multicolumn{4}{|c|}{ R $5020^{h}$} & \multirow{2}{*}{\multicolumn{2}{|c|}{$\begin{array}{c}\mathrm{DHT}^{b} \\
\text { (stable } \\
\text { transfection) }\end{array}$}} \\
\hline & \multicolumn{3}{|c|}{ Stable transfection } & \multirow{2}{*}{ 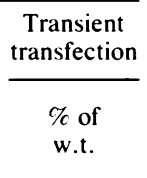 } & & \\
\hline & $\begin{array}{c}\text { No. } \\
\text { analyzed }\end{array}$ & $\begin{array}{l}\text { Fold } \\
\text { stimu- } \\
\text { lation }\end{array}$ & $\begin{array}{l}\% \text { of } \\
\text { w.t. }\end{array}$ & & $\begin{array}{c}\text { No. } \\
\text { analyzed }\end{array}$ & $\begin{array}{l}\text { Fold } \\
\text { stimu- } \\
\text { lation }\end{array}$ \\
\hline $\begin{array}{l}\text { w.t. } \\
196 / 186\end{array}$ & $1 P$ & $60 x$ & 100 & 100 & $1 \mathrm{P}$ & $7 x$ \\
\hline $\begin{array}{l}196 / 186 \\
190 / 181\end{array}$ & $2 \mathrm{P}$ & $28 x$ & 47 & $\begin{array}{l}101 \\
135\end{array}$ & $1 \mathrm{P}$ & $6 x$ \\
\hline $189 / 180$ & $1 \mathrm{P}$ & $31 x$ & 52 & 80 & $1 \mathrm{P}$ & $6 x$ \\
\hline $186 / 177$ & $2 \mathrm{P}$ & $30 x$ & 50 & 96 & $1 \mathrm{P}$ & $2.5 \mathrm{x}$ \\
\hline $181 / 175$ & & & & 132 & & \\
\hline $176 / 169$ & 1P & $35 x$ & 58 & & & \\
\hline $176 / 166$ & & & & 67 & & \\
\hline$D 193 / 162$ & $1 \mathrm{C}$ & $24 x$ & 40 & 54 & $1 \mathrm{C}$ & $2.7 x$ \\
\hline $161 / 145$ & & & & 131 & & \\
\hline $151 / 145$ & $3 \mathrm{C}$ & $32 x$ & 53 & 90 & $2 \mathrm{C}$ & $2.3 \mathrm{x}$ \\
\hline $151 / 145 \mathrm{SP}$ & $1 \mathrm{P}, 2 \mathrm{C}$ & $4 \mathrm{x}$ & 7 & & $1 \mathrm{P}, 2 \mathrm{C}$ & $1 x$ \\
\hline $140 / 132$ & & & & 150 & & \\
\hline$D 129 / 88$ & $1 \mathrm{P}$ & $2 \mathrm{x}$ & 3 & 28 & $1 \mathrm{P}$ & $1 x$ \\
\hline$D 129 / 88 \mathrm{DBS}+$ & & & & 15 & & \\
\hline $125 / 116$ & $1 \mathrm{P}$ & $<10 x$ & $<17$ & 40 & & \\
\hline $115 / 105$ & & & & 30 & & \\
\hline$D 101 / 78$ & & & & 10 & & \\
\hline $96 / 88$ & $1 \mathrm{P}, 2 \mathrm{C}$ & $20 x$ & 33 & 33 & $1 \mathrm{C}$ & $3 x$ \\
\hline $90 / 78$ & $1 \mathrm{P}$ & $8 x$ & 13 & 26 & $1 \mathrm{P}, 1 \mathrm{C}$ & $1.4 \mathrm{x}$ \\
\hline $90 / 70$ & $3 \mathrm{P}, 1 \mathrm{C}$ & $34 \mathrm{x}$ & 57 & 37 & & \\
\hline$D 193 / 78$ & & & & $<5$ & & \\
\hline
\end{tabular}

a T47D cells were transfected with the MMTV LTR/TK wild-type plasmid (w.t.) or its linker-scanning, deletion $(D)$, or insertion derivatives. SP denotes insertion of the 123-bp spacer (Fig. 1C). DBS + denotes insertion of a distal binding site in the correct orientation (Fig. 1B).

${ }^{b}$ The quantitation is based on densitometric scanning of the 142-nucleotide band of different autoradiographic exposures of $\mathrm{S} 1$ mapping experiments. For transient-transfection assays, the data were normalized to the $\beta$-globin internal standard and are based on three or more determinations. For stable-transfection assays, they were normalized to the content of cellular $\beta$-actin mRNA, and the number of pools $(\mathrm{P})$ or isolated clones $(\mathrm{C})$ analyzed is given.

lanes 25 and 26; Table 1). The mutant 90/78, which lacks half of the most proximal binding site including the 6-bp consensus sequence, produced a low progestin response in both stable and transient transfections (Fig. 2A, lane 12; Fig. 3a, lanes 28 and 29; Table 1).

Centered at nucleotide -70 is a sequence with an imperfect dyad symmetry that was shown to bind in vitro the ubiquitous nuclear protein termed TGGCA-binding protein, or NF-I (38). The mutant $90 / 70$, with a net deletion of $11 \mathrm{bp}$, has lost the $5^{\prime}$ half of the dyad symmetry along with the most proximal binding site for the progestin receptor. In transienttransfection assays it showed a slightly higher response than did the overlapping mutant $90 / 78$, in which the NF-I binding site is intact (Fig. 2A, lane 13; Table 1). In stably transfected cells (Fig. 3a, lanes 31 and 32; Fig. 3b, lanes 21 and 22) the progestin stimulation was significantly higher in mutant $90 / 70$ than in mutant $90 / 78$ (Table 1 ) in terms of the ratio between induced and control RNA levels. The apparent discrepancy may be eliminated if it is considered that the mutation in the NF-I site caused a reduction of approximately fourfold in the basal level of promoter activity in mouse $\mathrm{Ltk}^{-}$cells (6). In T47D cells transfected with the $90 / 70$ plasmid, the unstimulated level of transcription was indeed undetectable in two pools and one clone, despite a relatively high induced level

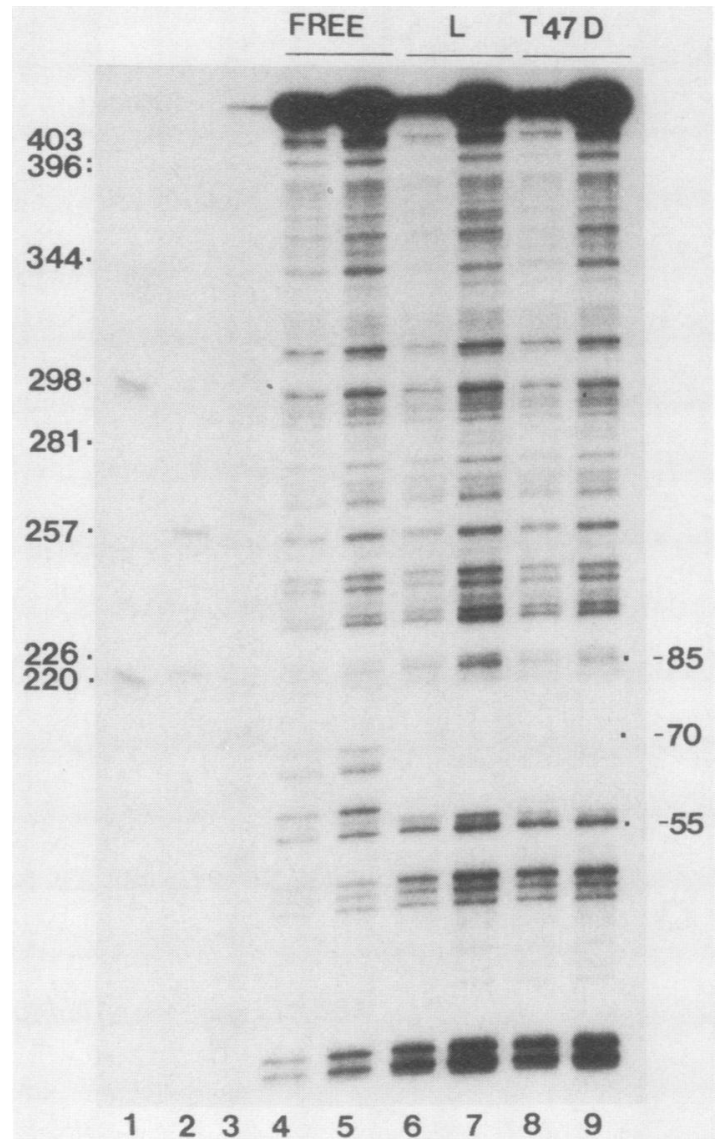

FIG. 4. DNase I footprint analysis of NF-I from T47D and Ltk cells on MMTV DNA. Two concentrations of nuclear extracts from Ltk $^{-}$cells (lanes 6 and 7) or T47D cells (lanes 8 and 9) were incubated with the probe DNA, labeled in the coding strand at the $3^{\prime}$ end of the LTR, and digested with DNase I. Lanes 4 and 5 show the pattern of free DNA incubated in the absence of nuclear extract. Lane 3 shows a $G+A$ sequencing ladder of the probe; lanes 1 and 2 contain molecular size markers as indicated on the left.

of RNA, and this might lead to a higher stimulation factor. DNase I in vitro footprinting analysis with nuclear extracts from T47D and $\mathrm{Ltk}^{-}$cells showed protection of the same sequences on wild-type MMTV DNA, between -80 and -58 from the cap site (Fig. 4), corresponding to the NF-I binding site (38). No DNase I protection in this area was observed on DNA of the $90 / 70$ mutant (6). In the region closer to the promoter, the mutant $37 / 11$ (which removes the TATA homology) gave extremely low levels of correctly initiated transcripts, even in the presence of progestin. They were accompanied by faint bands derived from transcripts with heterogeneous $5^{\prime}$ ends (data not shown). Finally, we tested the effect of disrupting the spatial arrangement of the distal versus the proximal regulatory domains on the ability of such mutants to respond to progestin. A relatively long DNA fragment with an unrelated sequence (a 123-bp HindIII fragment of mouse DNA [27]) was inserted at positions -151 to -145 (Fig. 1C). This resulted in a drastic reduction in R5020 stimulation (Fig. 2B, lane 3 versus lane 4; Table 1). The same spacer did not affect the response when inserted upstream of the distal element at position -192 (Fig. 2B, lane 1 versus lane 2), indicating that it did not have a general inhibitory effect on transcription. This suggests that the 
spacing between the distal and the proximal progestin regulatory elements plays a role in the response to the hormone.

Sequences required for the androgen-mediated response. Results for the androgen stimulation of the MMTV promoter were derived from the analysis of stably transfected cells, because of the higher sensitivity of the method. Still, the relatively weak response prevented any firm conclusions, and only a general pattern could be delineated. The data are shown in Fig. 3 and compiled in Table 1. In T47D cells transfected with the wild-type plasmid, the increase in the level of specific transcripts obtained after addition of $10^{-7} \mathrm{M}$ dihydrotestosterone was only approximately sevenfold, or about eightfold lower than for progestin stimulation. The results obtained with the mutant plasmids showed that, as for progestins, the sequences in the distal part of the HRE were only moderately important for androgen stimulation. Two plasmids with mutations between -190 and -180 were still able to mediate an androgen response within the normal range. A possible sensitive area is indicated by the mutant $176 / 169$, which in a pool of transfectants was transcribed 40-fold less well after androgen addition than after progestin addition (Fig. 3a, lanes 14 and 15), as opposed to 8-fold in the wild type. This mutation affects the consensus hexanucleotide of glucocorticoid and progesterone receptor-binding sites. The mutation $186 / 177$, located immediately upstream of the consensus sequence, caused a less than threefold reduction in androgen stimulation (Fig. 3a, lanes 10 and 12; Table 1), and, at least in the clone analyzed, a deletion that covers the whole distal region between -193 and -162 had a similar effect (Table 1). For the next $30 \mathrm{bp}$ from -160 to -130 , only the mutation $151 / 145$ was investigated, and in three independent clones it displayed a positive, although reduced, response to androgens. The insertion into this site of an unrelated sequence of 123 bp (mutant 151/145 ins spacer [27]) produced, as in the case of progestin, a strong negative effect and completely obliterated the testosterone response (Table 1), without affecting the base level of transcription.

In the proximal region, deletion of the two upstream consensus hexanucleotides (in plasmid 129/88 [Fig. 3a, lanes 19 and 21]) or mutation of the third one (in plasmid 90/78 [Fig. 3a, lanes 28 and 30]) abolished the androgen response (Table 1). A threefold induction was still present in a clone of cells containing about 15 copies of the plasmid $96 / 88$ (Fig. 3a, lanes 25 and 27; Table 1), whereas no signal with androgen was observed in another clone or in a pool that showed respectable amounts of progestin-induced RNA (data not shown). Compared with progestin, the androgen response was also extremely weak in transfectants with the 90/70 plasmid (Fig. 3a, lanes 32 and 33; Fig. 3b, lanes 22 and 23).

Glucocorticoid response in T47D cells cotransfected with the gene for its receptor. To compare the relative contributions of regulatory elements, we wanted to assess the extent of transcriptional stimulation by the synthetic glucocorticoid hormone dexamethasone in the same cells in which progestin and androgen effects were observed. T47D cells, which naturally do not respond to dexamethasone, were cotransfected with a plasmid expressing the human glucocorticoid receptor (pRSV-hGR $\alpha$ [16]) and some of the MMTV-tk plasmids. The level of expression of the introduced receptor gene in stably transfected cells was evaluated by quantitative S1 nuclease protection assays in which RNA annealed to a 5 '-end-labeled probe derived from the pRSV-hGR $\alpha$ plasmid and spanning the cap site was used (data not shown). This allowed the distinction between mRNA transcribed from the transfected plasmid and that endogenous to the cells, pre- sumably coding for a receptor which does not respond to dexamethasone. In this assay, comparable levels of glucocorticoid receptor mRNA were detected in the transfectants shown in Fig. 3b, with the exception of the pool 129/88, which had about sixfold-higher levels. It is therefore unlikely that differences in glucocorticoid stimulation were caused by different amounts of receptor in the cells. The results of the S1 mapping of MMTV-initiated RNA accumulated under stimulation by dexamethasone, as well as progestin and androgen, in such stable transfectants are shown in Fig. 3b. The pool of transfectants containing the wild-type MMTV LTR plasmid showed a much higher stimulation by dexamethasone than by the progestin R5020 (lane 4 versus lane 2). The inverse situation was found in cells harboring two different mutants in the distal receptor-binding site, 186/177 and 176/169 (lane 8 versus lane 6 and lane 12 versus lane 10), indicating a more drastic effect of the mutations on the glucocorticoid response. In a pool of transfectants with a deletion mutant lacking two of the three proximal receptorbinding sites (129/88), the levels of MMTV-specific transcripts were similar in the presence of dexamethasone and R5020 (Fig. 3b, lane 16 versus lane 14). Since about sixfold more glucocorticoid receptor was present in these cells than in the wild-type transfectant, the result suggests a strong reduction of the dexamethasone response. In the proximalbinding-site mutant $90 / 78$, the response to dexamethasone was slightly higher than that to R5020 (Fig. 3b, lane 20 versus lane 18), whereas it was strongly reduced in one pool and one isolated clone (lane 24 versus lane 22) containing the mutant in the NF-I binding site, $90 / 70$.

\section{DISCUSSION}

The results presented here show that within the $200 \mathrm{bp}$ upstream of the RNA start site of the MMTV LTR, distinct sequence elements are involved in the regulation of transcription by progestins and androgens, as well as glucocorticoids. Roughly, they can be located to a distal and a proximal area, analogous to the glucocorticoid regulatory elements defined previously by using mouse fibroblasts (5). The purified progesterone and glucocorticoid receptors were shown to cover the same sites on the MMTV DNA in exonuclease III protection assays (53), but clear differences in the details of the protein-DNA interactions, in particular in the promoter-proximal binding site, have been reported recently (11). Although the detailed functional analyses were performed with different cell types and may not be directly compared, a differential sensitivity to certain mutations in the progestin versus glucocorticoid response was apparent from a comparison of our present and previous $(5,27)$ studies. The use of exogenous glucocorticoid receptor provided by transfection to the mammary cells corroborated the notion that the distal regulatory element is more strongly involved in the response to glucocorticoids than to progestins and that an intact NF-I binding site is required for glucocorticoid but not for progestin action. Only tentative conclusions can be drawn for androgens, owing to the low stimulation levels observed. The data indicate a diffuse sensitivity to mutations, somewhat higher in the proximal region.

A weak distal control element for progestins may be defined by certain mutations in the area between -190 and -160 , but its boundaries cannot be precisely located (Table 1). The extent of impairment for the various mutants was only two- to threefold, the strongest impact possibly being associated with mutations in the hexanucleotide 5'-TGT 
TCT $-3^{\prime}$, which is conserved in all four receptor-binding sites. For glucocorticoids, in contrast, the distal element gave the most important contribution to the response: reductions of 10- to 20-fold with respect to the wild type were observed for some of the mutants in $\mathrm{Ltk}^{-}$fibroblasts (5) and similarly in T47D mammary cells cotransfected with the receptor gene (Fig. 3b). The segment from -160 to -130 appears rather insensitive to mutations. An indication that the distal receptor-binding site is nonetheless required for progestin and androgen is provided by the result of the insertion of a long spacer between distal and proximal elements, which strongly affected the progestin response and completely abolished the effect of androgen. The same fragment located at position -192 had no negative influence on transcription (Fig. 2B). This suggests that the effect of the spacer is due to the disruption of the relative arrangement of distal versus proximal regulatory elements, rather than to the presence of sequences contained in the inserted DNA. That physical interactions between receptors can occur was shown in an electron microscopy study (50) in which progesterone receptors appeared associated in pairs on the MMTV HRE. Using the same constructs, we observed a similar requirement for spacing of the elements in the glucocorticoid response in Ltk $^{-}$cells (6).

The promoter-proximal region (roughly between -128 and -78) contains the major regulatory element(s) for progestins and, possibly, androgens. Several plasmids with mutations in this area showed a reduced response to both hormones and were, on the whole, more strongly affected than plasmids with mutations in the distal region (Table 1). The plasmid $125 / 116$ is mutated at four positions between -121 and -117 in the conserved hexanucleotide, yet this sequence and the two other TGTTCT motifs of the proximal region are unaltered in plasmid $115 / 105$, which also gave a reduced progestin response. We conclude that a progestin regulatory element extends farther than the consensus sequence and possibly includes the whole in vitro footprint. The next two mutants (96/88 and 90/78) also had reduced progestin and androgen responses. The mutation in $96 / 88$ affects the middle receptor-binding site while leaving 5 of $6 \mathrm{bp}$ of the consensus sequence unaltered. The mutation in 90/78 largely removes the most proximal binding site, and, in addition, the net loss of $3 \mathrm{bp}$ causes a distortion in the stereospecific alignment between the upstream and the promoter regions. No such distortion occurs in the mutant 90/70, with a net deletion of $11 \mathrm{bp}$, or about 1 turn of the DNA helix. The observation that the mutant $90 / 70$ is less severely affected than $90 / 78$ may suggest that such an alignment is required in the proximal element for progestin regulation. A need for such steric relationships for optimal functioning of DNA sequences involved in interactions with proteins has been demonstrated for the simian virus 40 promoter (49) and for repressors bound at the $c$ I gene promoter of bacteriophage lambda (21). In two additional plasmids with mutations of the proximal region, two receptor-binding sites are simultaneously deleted: in the plasmid $129 / 88$ and in the plasmid $101 / 78$, with a net removal of 3 and 1.5 helix turns, respectively. Both gave a very low progestin stimulation. The insertion between -129 and -88 of a synthetic oligonucleotide with the sequence of the complete distal receptor-binding site did not restore the progestin stimulation (Fig. 2A), although this had been the case for the glucocorticoid response in $\mathrm{Ltk}^{-}$cells (27). This result further strengthens the conclusion that the distal element plays a lesser role in progestin stimulation than it does for glucocorticoids. As for the proximal receptor-binding site, our results show that it is more strongly involved in the progestin (and possibly androgen) responses. Concerning progestin regulation, a qualitatively similar conclusion can be drawn from two very recent studies on steroid hormone inducibility of identical sets of linker-scanning mutants transiently assayed in T47D cells $(9,11)$. In both cases, the lowest progestin stimulation was observed with a mutant altered in the proximal consensus hexanucleotide between -121 and -114 . However, a mutation between -110 and -103 had much less effect, whereas in our study the mutant $115 / 105$ was also significantly reduced in the progestin response. Since in both instances the consensus sequence is preserved, more precisely defined base mutations are needed to identify individual contributions of residues in this area. In the study that used the natural MMTV promoter (9), the smallest impact was of a mutation in the distal consensus hexanucleotide, in agreement with our observations. When comparing relative effects of the same mutations on the progestin and the glucocorticoid responses, the two reports disagree on the results for the distal as well as two proximal element mutants. Since the other study (11) used the HRE upstream of -70 linked to the herpes simplex virus $t k$ promoter, it remains to be seen whether the divergence can be attributed to the absence of the NF-I binding site or to the juxtaposition of heterologous promoters and enhancer elements.

Concerning the androgen response, we observed a reduction in all mutants with mutations downstream of -180 ; the effects of mutations or deletions appeared less pronounced in the distal than in the proximal region, but the overall stimulation was low, which made quantitation difficult. One of the above-mentioned studies (9) analyzed androgen effects in T47D cells that gave a higher response; an extremely strong reduction was found with all mutations tested, and a similar pattern was found with a glucocorticoid hormone other than dexamethasone that is recognized by the T47D cell receptor. The discrepancy between this set of data and ours may be explained by the different sequences used as mutations (CCCGGG or CAAGCTTG). With respect to glucocorticoids, the available data indicate that the relative importance of the proximal region may vary quantitatively depending on the cell type: the same plasmids (129/88 and 90/78) showed a stronger negative effect in T47D cells (Fig. 3b) than in $\mathrm{Ltk}^{-}$cells (5). Qualitatively, their relative impact was similar, in that the mutant $129 / 88$ gave a lower induction than 90/78; however, the latter gave results close to those for the wild type in $\mathrm{Ltk}^{-}$cells, although not in T47D cells (Fig. $3 b)$. Cell-specific differences in the sensitivity to mutations in the proximal element have also been observed by others $(9$, $11)$.

The comparison of the pair of mutants $90 / 78$ and $90 / 70$ reveals a clear difference in the requirement of progestins or glucocorticoids for a functional NF-I binding site. The mutant $90 / 70$, compared with $90 / 78$, lacks half of the NF-I recognition sequence (38) and does not bind NF-I in a DNase $I$ in vitro footprinting analysis with nuclear extracts, whereas 90/78 does (6). T47D cells also contain an NF-I binding activity (Fig. 4) that is required for the glucocorticoid response, in agreement with previous observations with Ltk $^{-}$cells (5) and human MCF-7 cells (35). The fact that the mutant $90 / 70$ did not cause any further reduction in progestin response than the mutant $90 / 78$ implies that an intact NF-I binding site is not required for progestin stimulation. A similar conclusion has been reached by others using a different mutant affecting NF-I binding (9). The glucocorticoid and progesterone receptors show extensive divergence in the amino-terminal portion of the molecule (19), which, in 
the case of the glucocorticoid receptor, has a modulating function $(16,22)$. One might speculate that the differential requirements of these two different steroids for the NF-I binding site reflect different interactions between NF-I (or other transcription factors) and receptor proteins, possibly involving their amino-terminal domains. The use of mutated receptors for the activation of wild-type and mutated LTRs may help elucidate the mechanisms of the postulated interactions.

Two recent reports $(20,48)$ provided evidence that a 15 -bp oligonucleotide with partial dyad symmetry taken from a glucocorticoid response element could act as a progestin-, androgen-, or glucocorticoid-stimulated enhancer and that point mutations in this sequence affected the response to the hormones in a similar manner in different responsive cells. This result may primarily reflect a high structural similarity in the DNA-binding domains of the respective receptors, as indicated by the high identity in amino acid sequence (reviewed in reference 19). In a steroid-induced gene, the actual arrangement of regulatory elements often comprises more than one receptor-binding site, in addition to sequences interacting with transcription factors of other kinds. A more subtle hormonal regulation may then be achieved by variations in the sequence context or in the distance and relative orientation of bound receptors to each other or to the factors. For these interactions, other portions of the receptor molecule are likely to be required. The data presented here support this notion of differential roles for each component of a set of regulatory elements.

\section{ACKNOWLEDGMENTS}

We thank Heidi Diggelmann for encouragement, support, and discussions; Blanka Kühnel for constructing some of the mutants: V. Giguère, and R. M. Evans for the plasmid pRSV-hGR $\alpha$; and Otto Hagenbüchle and John Cohen for critical reading of the manuscript. Pascal Cousin and Valérie Tâche contributed excellent technical assistance.

This work was supported by the Swiss National Science Foundation. P.L.G. was a recipient of a fellowship from the TaeckerStiftung and a Bourse de Chailly.

\section{LITERATURE CITED}

1. Banerji, J., S. Rusconi, and W. Schaffner. 1981. Expression of a $\beta$-globin gene is enhanced by remote SV40 DNA sequences. Cell 27:299-308.

2. Blöchlinger, K., and H. Diggelmann. 1984. Hygromycin B phosphotransferase as a selectable marker for DNA transfer experiments with higher eucaryotic cells. Mol. Cell. Biol. 4:29292931.

3. Buetti, E., and H. Diggelmann. 1981. Cloned mouse mammary tumor virus DNA is biologically active in transfected mouse cells and its expression is stimulated by glucocorticoid hormones. Cell 23:335-345.

4. Buetti, E., and H. Diggelmann. 1983. Glucocorticoid regulation of mouse mammary tumor virus: identification of a short essential DNA region. EMBO J. 2:1423-1429.

5. Buetti, E., and B. Kühnel. 1986. Distinct sequence elements involved in the glucocorticoid regulation of the mouse mammary tumor virus promoter identified by linker scanning mutagenesis. J. Mol. Biol. 190:379-389.

6. Buetti, E., B. Kühnel, and H. Diggelmann. 1989. Dual function of a nuclear factor I binding site in MMTV transcription regulation. Nucleic Acids Res. 17:3065-3078.

7. Cato, A. C. B., D. Henderson, and H. Ponta. 1987. The hormone response element of the mouse mammary tumor virus DNA mediates the progestin and androgen induction of transcription in the proviral long terminal repeat region. EMBO J. 6:363-368.

8. Cato, A. C. B., R. Miksicek, G. Schütz, J. Arnemann, and M. Beato. 1986. The hormone regulatory element of mouse mam- mary tumor virus mediates progesterone induction. EMBO J. 5:2237-2240.

9. Cato, A. C. B., P. Skroch, J. Weinmann, P. Butkeraitis, and H. Ponta. 1988. DNA sequences outside the receptor-binding sites differentially modulate the responsiveness of the mouse mammary tumour virus promoter to various steroid hormones. EMBO J. 7:1403-1410.

10. Chalbos, D., and H. Rochefort. 1984. Dual effects of the progestin R5020 on proteins released by the T47D human breast cancer cells. J. Biol. Chem. 259:1231-1238.

11. Chalepakis, G., J. Arnemann, E. Slater, H.-J. Brüller, B. Gross, and M. Beato. 1988. Differential gene activation by glucocorticoids and progestins through the hormone regulatory element of mouse mammary tumor virus. Cell 53:371-382.

12. Darbre, P., M. Page, and R. J. B. King. 1986. Androgen regulation by the long terminal repeat of mouse mammary tumor virus. Mol. Cell. Biol. 6:2847-2854.

13. Fasel, N., K. Pearson, E. Buetti, and H. Diggelmann. 1982. The region of mouse mammary tumor virus DNA containing the long terminal repeat includes a long coding sequence and signals for hormonally regulated transcription. EMBO J. 1:3-7.

14. Feinberg, A. P., and B. Vogelstein. 1983. A technique for radiolabeling DNA restriction endonuclease fragments to high specific activity. Anal. Biochem. 132:6-13.

15. Galas, D., and A. Schmitz. 1978. DNase footprinting: a simple method for the detection of protein-DNA-binding specificity. Nucleic Acids Res. 5:3157-3170.

16. Giguère, V., S. M. Hollenberg, M. G. Rosenfeld, and R. M. Evans. 1986. Functional domains of the human glucocorticoid receptor. Cell 46:645-652.

17. Gorski, K., M. Carneiro, and U. Schibler. 1986. Tissue-specific in vitro transcription from the mouse albumin promoter. Cell 47:767-776.

18. Graham, F. L., S. Bacchetti, R. McKinnon, C. Stanners, B. Cordell, and H. M. Goodman. 1980. Transformation of mammalian cells with DNA using the calcium technique, p. 3-25. In R. Baserga, C. Croce, and G. Rovera (ed.), Introduction of macromolecules into viable mammalian cells. Alan R. Liss, Inc., New York.

19. Green, S., and P. Chambon. 1986. A superfamily of potentially oncogenic hormone receptors. Nature (London) 324:615-617.

20. Ham, J., A. Thomson, M. Needham, P. Webb, and M. Parker. 1988. Characterization of response elements for androgens, glucocorticoids and progestins in mouse mammary tumour virus. Nucleic Acids Res. 16:5263-5276.

21. Hochschild, A. H., and M. Ptashne. 1986. Cooperative binding of lambda repressors to sites separated by integral turns of the DNA helix. Cell 44:681-687.

22. Hollenberg, S. M., V. Giguère, P. Segui, and R. M. Evans. 1987. Colocalization of DNA-binding and transcriptional activation functions in the human glucocorticoid receptor. Cell 49:39-46.

23. Hollenberg, S. M., C. Weinberger, E. S. Ong, G. Cerelli, A. Oro, R. Lebo, E. B. Thompson, M. G. Rosenfeld, and R. M. Evans. 1985. Primary structure and expression of a functional human glucocorticoid receptor cDNA. Nature (London) 318:635-641.

24. Horwitz, K. B., D. T. Zava, A. K. Thilagar, E. M. Jensen, and W. L. McGuire. 1978. Steroid receptor analyses of nine human breast cancer cell lines. Cancer Res. 38:2434-2437.

25. Huang, A. L., M. C. Ostrowski, D. Berard, and G. L. Hager. 1981. Glucocorticoid regulation of the Ha-MuSV p21 gene conferred by sequences from mouse mammary tumor virus. Cell 27:245-255.

26. Hynes, N., A. J. J. van Ooyen, N. Kennedy, P. Herrlich, H. Ponta, and B. Groner. 1983. Subfragments of the large terminal repeat cause glucocorticoid-responsive expression of mouse mammary tumor virus and of an adjacent gene. Proc. Natl. Acad. Sci. USA 80:3637-3641.

27. Kühnel, B., E. Buetti, and H. Diggelmann. 1986. Functional analysis of the glucocorticoid regulatory elements present in the mouse mammary tumor virus long terminal repeat. A synthetic distal binding site can replace the proximal binding domain. $J$. Mol. Biol. 190:367-378.

28. Lee, F., R. Mulligan, P. Berg, and G. Ringold. 1981. Glucocor- 
ticoids regulate expression of dihydrofolate reductase cDNA in mouse mammary tumour virus chimaeric plasmids. Nature (London) 294:228-232.

29. Lichtsteiner, S., J. Wuarin, and U. Schibler. 1987. The interplay of DNA-binding proteins on the promoter of the mouse albumin gene. Cell 51:963-973.

30. Luthmann, H., and G. Magnusson. 1983. High efficiency polyoma DNA transfection of chloroquine treated cells. Nucleic Acids Res. 11:1295-1308.

31. Majors, J., and H. E. Varmus. 1983. A small region of the mouse mammary tumor virus long terminal repeat confers glucocorticoid hormone regulation on a linked heterologous gene. Proc. Natl. Acad. Sci. USA 80:5866-5870.

32. Maniatis, T., E. F. Fritsch, and J. Sambrook. 1982. Molecular cloning: a laboratory manual. Cold Spring Harbor Laboratory, Cold Spring Harbor, N.Y.

33. Maniatis, T., R. C. Hardison, E. Lacy, J. Lauer, C. O'Connell, and D. Quon. 1978. The isolation of structural genes from libraries of eucaryotic DNA. Cell 15:687-701.

34. Maxam, A. M., and W. Gilbert. 1980. Sequencing end-labeled DNA with base-specific chemical cleavages. Methods Enzymol. 65:499-560.

35. Miksicek, R., U. Borgmeyer, and J. Nowock. 1987. Interaction of the TGGCA-binding protein with upstream sequences is required for efficient transcription of mouse mammary tumor virus. EMBO J. 6:1355-1360.

36. Minty, A. J., S. Alonso, J. L. Guénet, and M. E. Buckingham. 1983. Number and organization of actin-related sequences in the mouse genome. J. Mol. Biol. 167:77-101.

37. Neumann, E., M. Schaefer-Ridder, Y. Wang, and P. H. Hofschneider. 1982. Gene transfer into mouse lyoma cells by electroporation in high electric fields. EMBO J. 1:841-845.

38. Nowock, J., U. Borgmeyer, A. W. Püschel, R. A. W. Rupp, and A. E. Sippel. 1985. The TGGCA protein binds to the MMTV LTR, the adenovirus origin of replication and the BK virus enhancer. Nucleic Acids Res. 13:2045-2061.

39. Payvar, F., D. DeFranco, G. L. Firestone, B. Edgar, O. Wrange, S. Okret, J. A. Gustafsson, and K. R. Yamamoto. 1983. Sequence-specific binding of glucocorticoid receptor to MMTV DNA at sites within and upstream of the transcribed region. Cell 35:381-392.

40. Ponta, H., N. Kennedy, P. Skroch, N. E. Hynes, and B. Groner. 1985. The hormonal response region in the mouse mammary tumor virus long terminal repeat can be dissociated from the proviral promoter and has enhancer properties. Proc. Natl. Acad. Sci. USA 82:1020-1024.

41. Ringold, G. M. 1985. Steroid hormone regulation of gene expression. Annu. Rev. Pharmacol. Toxicol. 25:529-566.

42. Ringold, G. M., K. R. Yamamoto, J. M. Bishop, and H. E.
Varmus. 1977. Glucocorticoid-stimulated accumulation of mouse mammary tumor virus RNA: increased rate of synthesis of viral RNA. Proc. Natl. Acad. Sci. USA 74:2879-2883.

43. Scheidereit, C., and M. Beato. 1984. Contacts between hormone receptor and DNA double helix within a glucocorticoid regulatory element of mouse mammary tumor virus. Proc. Natl. Acad. Sci. USA 81:3029-3033.

44. Scheidereit, C., S. Geisse, H. M. Westphal, and M. Beato. 1983. The glucocorticoid receptor binds to defined nucleotide sequences near the promoter of mouse mammary tumour virus. Nature (London) 304:749-752.

45. Siebenlist, U., L. Hennighausen, J. Battey, and P. Leder. 1984. Chromatin structure and protein binding in the putative regulatory region of the c-myc gene in Burkitt lymphoma. Cell 37:381-391.

46. Southern, E. M. 1975 . Detection of specific sequences among DNA fragments separated by gel electrophoresis. J. Mol. Biol. 98:503-517.

47. Southern, P. J., and P. Berg. 1982. Transformation of mammalian cells to antibiotic resistance with a bacterial gene under control of the SV40 early region promoter. J. Mol. Appl. Genet. 1:327-341.

48. Strähle, U., G. Klock, and G. Schütz. 1987. A DNA sequence of 15 base pairs is sufficient to mediate both glucocorticoid and progesterone induction of gene expression. Proc. Natl. Acad. Sci. USA 84:7871-7875.

49. Takahashi, K., M. Vigneron, H. Matthes, A. Wildeman, M. Zenke, and P. Chambon. 1986. Requirement of stereospecific alignments for initiation from the simian virus 40 early promoter. Nature (London) 319:121-126.

50. Théveny, B., A. Bailly, C. Rauch, M. Rauch, E. Delain, and E. Milgrom. 1987. Association of DNA-bound progesterone receptors. Nature (London) 329:79-81.

51. Van Nie, R., and A. Dux. 1971. Biological and morphologica characteristics of mammary tumors in GR mice. J. Natl. Cance Inst. 46:885-897.

52. Varmus, H. E., N. Quintrell, E. Medeiros, J. M. Bishop, R. C. Nowinski, and N. H. Sarkar. 1973. Transcription of mouse mammary tumor virus genes in tissues from high and low tumor incidence mouse strains. J. Mol. Biol. 79:663-679.

53. Von der Ahe, D., S. Janich, C. Scheidereit, R. Renkawitz, G. Schütz, and M. Beato. 1985. Glucocorticoid and progesterone receptors bind to the same sites in two hormonally regulated promoters. Nature (London) 313:706-709.

54. Yamamoto, K. R. 1985. Steroid receptor regulated transcription of specific genes and gene networks. Annu. Rev. Genet. 19: 209-252.

55. Young, H. A., T. Y. Shih, E. M. Scolnick, and W. P. Parks. 1977 Steroid induction of mouse mammary tumor virus: effect upon synthesis and degradation of viral RNA. J. Virol. 21:139-146. 